\title{
Addressing Disciplinary Misconceptions: Mentorship Programs and Student-Led Surgical Societies. Comment on "Perception of Plastic Surgery and the Role of Media Among Medical Students: Cross-Sectional Study"
}

Grace Olivia Jane Poole, BSc; Naomi Melamed, BSc; Ella Hubbard, BA

St George's University of London, London, United Kingdom

Corresponding Author:

Grace Olivia Jane Poole, BSc

St George's University of London

Cranmer Terrace

Tooting

London, SW170RE

United Kingdom

Phone: 447807831588

Email: gracepoole06@icloud.com

Related Article:

Comment on: https://www.i-jmr.org/2019/2/e12999/

(Interact J Med Res 2021;10(1):e17237) doi: 10.2196/17237

\section{KEYWORDS}

medical education; plastic surgery; students

We would like to thank Mortada et al [1] for their recent article, highlighting the misconceptions of plastic surgery among medical students. Upon reading the article, we were surprised by the lack of awareness reported among both female and male students.

As the authors highlighted, medical students generally possess a poor understanding of what plastic surgery entails. These results are not unique to Saudi Arabia, with analysis of medical schools in both the United Kingdom and Canada indicating that students are unaware of the full breadth of operations plastic surgeons perform, including the management of pressure ulcers, cleft palate, and carpal tunnel syndrome [2,3]. Given the competitive nature of plastic surgery globally, it is important that students begin to construct competitive portfolios early [4]. However, if students are unaware of the full range and utility of plastic surgery, it is questionable how they may be expected to do so. Moreover, only $26 \%$ of qualified doctors would refer neuronal injuries of the hand to plastic surgeons [5]. This highlights a fundamental gap in the understanding of plastic surgery among both students and qualified practitioners.

We recognize that many students engage with medical television programs and agree that accurate multimedia representation of plastic surgery is important. However, we disagree that television represents a viable tool to promote student awareness of the full range, complexity, and utility of plastic surgery. In fact, there is evidence that television representation of plastic surgery may actively contribute to a skewed understanding of the specialty among medical students [3]. Similarly, content on social media is likely to reinforce existing misconceptions around the work of plastic surgeons, with research suggesting that surgeons with a cosmetic focus to their practice are more likely to utilize social media [6]. Furthermore, content on social media platforms is unregulated, and the reliability of information cannot be guaranteed.

We propose that there are more effective strategies to promote student understanding of plastic surgery. Exposure to plastic surgery during medical school has been shown to increase matriculation into the specialty; yet only $29.4 \%$ of students report such exposure [2,7]. One method shown to effectively overcome this gap in the formal curriculum is extracurricular mentorship programs. Within these programs, students can shadow plastic surgeons in their clinical environment, gaining insights into the realities of the specialty [8]. In addition, there is a clear role to be played by proactive interaction with student-led surgical societies. Student-organized career sessions allow trainees to deliver accurate information on the variety, demands, and rewards of a career in plastic surgery. Mentorship programs and society-organized careers sessions both enable students to develop a realistic understanding of plastic surgery and offer the opportunity for students to develop competitive portfolios.

Overall, we agree with Mortada et al [1] that students possess an inadequate understanding of plastic surgery. However, we propose that more effective strategies to overcome this would 
include mentorship programs and student-led surgical societies, on television and social media. rather than potentially skewed representations of the specialty

\section{Editorial Notice}

The corresponding author of "Perception of Plastic Surgery and the Role of Media Among Medical Students: Cross-Sectional Study" did not respond to our invitation to reply to this commentary.

\section{Conflicts of Interest}

None declared.

\section{References}

1. Mortada HH, Alqahtani YA, Seraj HZ, Albishi WK, Aljaaly HA. Perception of Plastic Surgery and the Role of Media Among Medical Students: Cross-Sectional Study. Interact J Med Res ;8(2):e12999 [FREE Full text] [doi: 10.2196/12999] [Medline: 30942694]

2. Farid M, Vaughan R, Thomas S. Plastic Surgery Inclusion in the Undergraduate Medical Curriculum: Perception, Challenges, and Career Choice-A Comparative Study. Plast Surg Int 2017;2017:9458741 [FREE Full text] [doi: 10.1155/2017/9458741] [Medline: 28630768]

3. Fraser S, Al Youha S, Rasmussen PJ, Williams JG. Medical Student Perception of Plastic Surgery and the Impact of Mainstream Media. Plast Surg (Oakv) 2017 Feb;25(1):48-53 [FREE Full text] [doi: 10.1177/2292550317694844] [Medline: 29026812]

4. Morzycki A, Bezuhly M, Williams JG. How Competitive Is Plastic Surgery? An Analysis of the Canadian and American Residency Match. Plast Surg (Oakv) 2018 Feb;26(1):46-51 [FREE Full text] [doi: 10.1177/2292550317749507] [Medline: 29619359]

5. Panse N, Panse S, Kulkarni P, Dhongde R, Sahasrabudhe P. Awareness and Perception of Plastic Surgery among Healthcare Professionals in Pune, India: Do They Really Know What We Do? Plast Surg Int 2012;2012:962169 [FREE Full text] [doi: 10.1155/2012/962169] [Medline: 22685647]

6. Vardanian AJ, Kusnezov N, Im DD, Lee JC, Jarrahy R. Social media use and impact on plastic surgery practice. Plast Reconstr Surg 2013 May;131(5):1184-1193. [doi: 10.1097/PRS.0b013e318287a072] [Medline: 23629099]

7. Agarwal JP, Mendenhall SD, Moran LA, Hopkins PN. Medical student perceptions of the scope of plastic and reconstructive surgery. Ann Plast Surg 2013 Mar;70(3):343-349. [doi: 10.1097/SAP.0b013e31823b6c19] [Medline: 23038146]

8. Barker JC, Rendon J, Janis JE. Medical Student Mentorship in Plastic Surgery: The Mentee's Perspective. Plast Reconstr Surg 2016 Jun;137(6):1934-1942. [doi: 10.1097/PRS.0000000000002186] [Medline: 27219246]

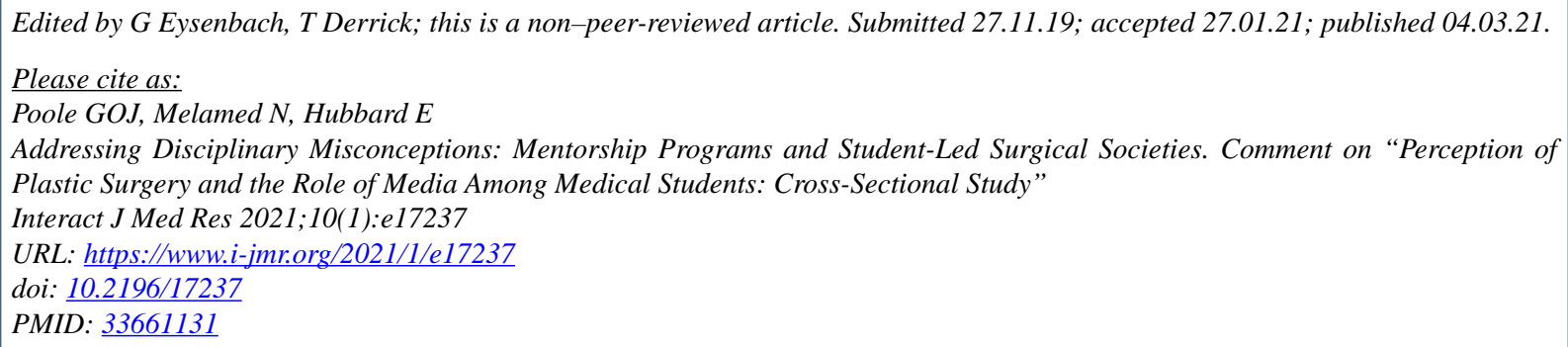

(C) Grace Olivia Jane Poole, Naomi Melamed, Ella Hubbard. Originally published in the Interactive Journal of Medical Research (http://www.i-jmr.org/), 04.03.2021. This is an open-access article distributed under the terms of the Creative Commons Attribution License (https://creativecommons.org/licenses/by/4.0/), which permits unrestricted use, distribution, and reproduction in any medium, provided the original work, first published in the Interactive Journal of Medical Research, is properly cited. The complete bibliographic information, a link to the original publication on http://www.i-jmr.org/, as well as this copyright and license information must be included. 